\title{
Mark DARLOW et Yann ROBERT, Laya. L'Ami des lois
}

Londres, Modern Humanities Research Association, 2011, 378 p.

\section{Michel Biard}

\section{OpenEdition}

1 Journals

\section{Édition électronique}

URL : https://journals.openedition.org/ahrf/12658

DOI : $10.4000 / a h r f .12658$

ISSN : 1952-403X

Éditeur :

Armand Colin, Société des études robespierristes

\section{Édition imprimée}

Date de publication : 1 septembre 2012

Pagination : 178-180

ISBN : 978-2-200-92761-5

ISSN : 0003-4436

\section{Référence électronique}

Michel Biard, "Mark darlow et Yann robert, Laya. L'Ami des lois », Annales historiques de la Révolution française [En ligne], 369 | juillet-septembre 2012, mis en ligne le 28 février 2013, consulté le 22 avril 2022. URL : http://journals.openedition.org/ahrf/12658; DOI : https://doi.org/10.4000/ahrf.12658

Ce document a été généré automatiquement le 22 avril 2022.

Tous droits réservés 


\title{
Mark DARLOW et Yann ROBERT, Laya. L'Ami des lois
}

Londres, Modern Humanities Research Association, 2011, 378 p.

\author{
Michel Biard
}

\section{RÉFÉRENCE}

Mark DARLOW et Yann ROBERT, Laya. L'Ami des lois, Londres, Modern Humanities Research Association, 2011, 378 p., ISBN 9781907322440, 11,99€

1 Ce nouveau volume de la collection Phoenix, consacrée au théâtre français du XVIII ${ }^{\mathrm{e}}$ siècle, vient rappeler avec bonheur le rôle important joué par cette pièce de Laya au tout début de 1793, tant sur la question de la censure théâtrale que sur celle des affrontements politiques entre Girondins et Montagnards. Ce double fil conducteur n'est jamais perdu de vue par les deux auteurs, Mark Darlow (Senior Lecturer à l'Université de Cambridge) et Yann Robert (chercheur postdoctoral, auteur d'une thèse intitulée Living Theater: Politics, justice and the stage in France [1750-1800]). Ils nous donnent là une solide publication scientifique du texte de la pièce, assortie de notes indiquant les variantes des diverses éditions (trois éditions chez Maradan et neuf éditions identifiées comme des contrefaçons, le tout en 1793 ; une en 1795, une autre en 1822 et une dernière en 1824) et du manuscrit de souffleur conservé à la bibliothèque de la Comédie-Française. En annexes, on découvrira la fortune critique de la pièce dans la presse parisienne de janvier et février 1793, ainsi que les débats politiques retrouvés là aussi dans les journaux, mais également dans divers textes imprimés et dans les procès-verbaux de la Convention nationale (par l'intermédiaire des Archives parlementaires). Enfin et surtout, l'ouvrage comprend une copieuse introduction de 120 pages, fondamentale pour qui entend saisir les tenants et aboutissants des querelles suscitées par cette pièce de théâtre.

2 Après une brève présentation de Laya et de son œuvre, les auteurs évoquent les conditions des premières représentations de la pièce à Paris, au Théâtre de la Nation, 
ci-devant Théâtre-Français. Né en décembre 1761, Laya fait alors figure d'auteur peu connu (malgré deux écrits publiés en 1789) lorsque son texte est accepté par les comédiens de ce Théâtre prestigieux, le $1^{\mathrm{er}}$ décembre 1792 . Si des rumeurs politiques ont pu circuler dès décembre sur cette "prétendue comédie ", comme le soutiennent les Révolutions de Paris, les premières représentations ne suscitent guère de troubles. Cela étant, l'évolution même des recettes illustre l'intérêt grandissant des spectateurs, intérêt qui ne saurait être uniquement littéraire : 2233 livres le 2 janvier 1793, 5305 deux jours après, 6696 le 7 et 6624 le 10... là où, les autres jours, la reprise de pièces anciennes entrâne des recettes de 777 à 3474 livres. Le 11 janvier, la Commune de Paris décide d'ordonner la suspension des représentations, ordre aussitôt cassé par la Convention nationale et qui n'empêche donc pas qu'une nouvelle représentation soit donnée le 12. La tentative de censure n'apparaît pas, à ce moment, comme une véritable nouveauté. En effet, la censure des théâtres, qui avait disparu grâce à la Révolution, a effectué un premier retour dès 1792. En mars de cette année, autrement dit à la veille de la déclaration de guerre, la Commune a interdit Adrien, opéra de Méhul, dans le livret duquel figuraient des parallèles flatteurs entre l'empereur romain de la lointaine Antiquité et l'empereur autrichien de la très brûlante actualité. Mieux, peu de temps auparavant, le 25 février, un député du Calvados, Henry-Larivière, était intervenu pour réclamer des mesures contre les théâtres «inciviques »... Si l'on ajoute qu'Henry-Larivière appartient à la mouvance girondine, il devient pour le moins difficile d'incriminer les seuls Montagnards et Jacobins comme responsables du retour insidieux de la censure des théâtres. Tout comme la mise à l'écart des Girondins par la force les 31 mai et 2 juin 1793 a de facto eu pour antécédents leur propre volonté d'épurer la Convention de Marat et de quelques autres Montagnards, la censure de 1793 ne saurait donc être assimilée à une sorte de coup de tonnerre dans un ciel serein. Quoi qu'il en soit, après de nouveaux troubles le 15 janvier, et bien que la pièce ne soit toujours pas interdite, la troupe du Théâtre de la Nation préfère prudemment la retirer de l'affiche. Aussi le couperet littéraire ne tombe-t-il finalement que le 31 mars 1793, alors même que l'œuvre n'est plus jouée. Comme la Convention demande à ce moment à la Commune d'interdire Mérope, tragédie de Voltaire, coupable d'avoir suscité des "applications» et donc des troubles au Théâtre Montansier, la Commune saisit l'occasion pour interdire d'un même élan Mérope et L'Ami des lois. Laya, décrété d'arrestation (à une date non indiquée dans l'ouvrage), doit se cacher pendant quinze mois pour échapper à la prison et sa pièce ne revient sur la scène que le 6 juin 1795 .

3 Laya a tout d'abord prétendu que sa comédie n'avait rien de politique, là où tout un chacun en profitait pourtant pour se gausser des Jacobins, tandis que les spectateurs n'avaient aucun mal à assimiler les personnages de Duricrâne à Marat et de Nomophage (traduisez "mangeur des lois ») à Robespierre. Assimilation si aveuglante qu'Augustin Robespierre lui-même protesta contre la caricature ainsi réservée à son aîné. Selon Laya, sa pièce ne faisait que s'inscrire dans une longue tradition, celle d'Aristophane et celle de Molière, de la comédie de mœurs et de caractères. Autrement dit, ses buts n'étaient pas politiques, mais moraux ; son texte ne s'attaquait point à des hommes ou à des factions, mais à des "ridicules». Toutefois, d'autres aspects pouvaient eux aussi susciter des réserves, des critiques, voire des troubles. En un moment où les nobles tendaient soit à disparaître des théâtres, soit à devenir la cible de satires plus ou moins féroces, Laya entendait montrer qu'un noble, à l'exemple de son baron de Versac, pouvait encore être converti par la seule force de la Raison et à terme se rallier à la Révolution. Volonté de défendre ici un théâtre "tolérant» contre un théâtre 
«militant »? Voire... car, comme le font observer avec justesse les deux auteurs, Laya utilise bel et bien le "style dénonciateur " contre les Jacobins et crée donc une pièce militante, quand bien même il s'en défend. À cet égard, ils suggèrent un rapprochement avec Les Philosophes, comédie de Palissot dans laquelle les philosophes attaqués «sont plus criminels qu'ils ne sont ridicules : en cela ils ressemblent aux Jacobins de L'Ami des lois» (p. 68). Si l'on ajoute le contexte du procès de Louis XVI, l'un des enjeux du moment entre Montagnards et Girondins, tout plaide en faveur d'une innocence fort douteuse de Laya. Mieux, en 1814, loin de reprendre son plaidoyer en faveur d'une pièce républicaine assassinée par Montagnards et Jacobins, Laya présente L'Ami des lois comme un ouvrage qui était royaliste et qu'il avait dû déguiser sous un travestissement républicain en raison des circonstances de l'hiver 1792. De 1814 à 1822, Laya officie au Bureau des Théâtres, autrement dit devient... censeur! Ajoutons qu'en 1817 il fait son entrée à l'Académie française. Prix de son ralliement, diront les " mauvaises langues ».

4 Au chapitre des regrets, mentionnons quelques erreurs qui auraient pu aisément être évitées dans ce travail par ailleurs passionnant (le Comité de salut public ne prend pas des décrets, mais des arrêtés; Mamidal au lieu de Mavidal), quelques lacunes bibliographiques pour le moins surprenantes à ce niveau scientifique (pour ne citer qu'un exemple, sous la rubrique "Ouvrages récents sur le théâtre révolutionnaire », on cherche en vain les actes des divers colloques publiés ces dernières années sous la direction de Philippe Bourdin), enfin des passages qui auraient demandé à être infiniment nuancés. Passe encore que l'on évoque "l'anarchie jacobine » sous le Directoire, sans utiliser de guillemets et sans préciser à qui attribuer le stigmatisant. En revanche, que pensera du passage suivant un lecteur non averti : «à partir de 1793 seront éliminés le droit de l'accusé à la parole, les témoins et les avocats pour la défense, les jurés, et même les preuves matérielles » (p. 84-85) ? Histoire littéraire et histoire de la justice ne se rencontrent pas assez souvent, j'en conviens sans peine, mais au minimum faudrait-il prendre la précaution de consulter quelques ouvrages de référence avant d'écrire de semblables aberrations, sous peine de tout confondre. 